\title{
A scenario for the generation process of the 2011 Tohoku earthquake based on dynamic rupture simulation: Role of stress concentration and thermal fluid pressurization
}

\author{
Yuta Mitsui ${ }^{1}$, Yoshihisa Iio $^{2}$, and Yukitoshi Fukahata ${ }^{2}$ \\ ${ }^{1}$ Department of Natural History Sciences, Graduate School of Science, Hokkaido University, Sapporo 060-0810, Japan \\ ${ }^{2}$ Research Center for Earthquake Prediction, Disaster Prevention Research Institute, Kyoto University, Uji 611-0011, Japan
}

(Received December 27, 2011; Revised April 26, 2012; Accepted May 24, 2012; Online published January 28, 2013)

\begin{abstract}
We perform dynamic rupture simulations to improve the understanding of the generation process of the 2011 Tohoku earthquake. We assume a dynamic weakening mechanism (dynamic thermal pressurization of pore fluid, hereinafter called TP) on the fault plane to represent nonlinear weakening friction, and take into account the shear stress changes before the Tohoku earthquake, due to the four $M$ 7-class earthquakes that occurred during 20032011. To constrain the dynamic rupture simulation, the moment release rate obtained by seismic slip inversions is referred. The simulation result implies the following about the 2011 Tohoku earthquake: (1) The rupture around the hypocenter was enhanced by the stress accumulation due to the preceding $M$ 7-class earthquakes. (2) The enhanced rupture triggered the TP mechanism in the near-trench area causing large slip, which promoted propagation of the rupture over a wide region including the source areas of the $M 7$-class earthquakes and surrounding conditionally-stable areas. (3) Without sufficient stress accumulation, the moment release of the Tohoku earthquake ended as an $M$ 8-class earthquake. (4) TP in the near-trench area should be effective but moderate. The occurrence time of the next megaquake would be strongly affected by the nonlinear effects of TP and the stress conditions. Thus, our model may contradict the concept of the (quasi-)cyclic occurrence of $M 9$ earthquakes.
\end{abstract}

Key words: 2011 Tohoku earthquake, stress accumulation, thermal fluid pressurization, moment-rate function.

\section{Introduction}

A giant earthquake, the 2011 off the Pacific Coast of Tohoku earthquake (hereafter called the Tohoku earthquake), occurred at the subduction plate boundary east of northern Honshu on March 11, 2011. Its magnitude, $M_{\mathrm{w}}$ 9.0, was far larger than the previous $M 7$-class earthquakes in the region (Yamanaka and Kikuchi, 2004; Uchida and Matsuzawa, 2011). Such a giant event had not previously been reported, with the exception of geological studies of tsunami deposits (e.g., Minoura et al., 2001).

Several GPS inversion studies using an on-land GPS network (e.g. Ito et al., 2000; Nishimura et al., 2004; Suwa et al., 2006; Hashimoto et al., 2009) proposed that the source region of the 2011 Tohoku earthquake had been locked (a clearly slower slip rate on the plate interface than the plate convergence rate) in aggregate, at least prior to 2003, when an $M 7$-class earthquake occurred in this region. Studies of small repeating earthquakes (Uchida et al., 2006; Uchida and Matsuzawa, 2011) also implied a locked fault. Moreover, Yamanaka and Kikuchi (2004) mentioned that the $M 7$-class earthquakes in this region did not fully release the accumulated slip due to the plate convergence. Mitsui and Iio (2011) suggested that locked conditions had contin-

Copyright (C) The Society of Geomagnetism and Earth, Planetary and Space Sciences (SGEPSS); The Seismological Society of Japan; The Volcanological Society of Japan; The Geodetic Society of Japan; The Japanese Society for Planetary Sciences; TERRAPUB.

doi:10.5047/eps.2012.05.016 ued until the occurrence of the Tohoku earthquake, except in the areas of the $M 7$-class earthquakes and their afterslip. However, such scenarios are only applicable in a region deeper than the hypocenter of the 2011 Tohoku earthquake and conditions in the shallower part have not been well resolved because of the power lack of on-land GPS stations to constrain near-trench slip (Loveless and Meade, 2011) and the absence of small repeating earthquakes near the trench.

Based on such observations, several studies have already discussed the generation mechanism of the Tohoku earthquake in terms of earthquake cyclicity (Hori and Miyazaki, 2011; Kato and Yoshida, 2011; Mitsui and Iio, 2011; Ohtani et al., 2011; Shibazaki et al., 2011; Mitsui et al., 2012). However, these studies did not properly consider the dynamic rupture process of the 2011 Tohoku earthquake. In addition, note that the (quasi-)cyclic occurrence of megaquakes is not guaranteed in this region. Clear evidence of previous $M 9$ earthquakes in this region has not been found. A geological study of tsunami deposits (Minoura et al., 2001) proposed that the 869 Jogan tsunami was caused by an $M 8.3$ earthquake, probably smaller than the $M 9$ Tohoku earthquake. Many tensile cracks at the ocean bottom around the trench were induced by the Tohoku earthquake (Tsuji et al., 2011), but no evidence has been found of similar cracks induced by a previous megaquake.

The rupture process of the Tohoku earthquake has also 


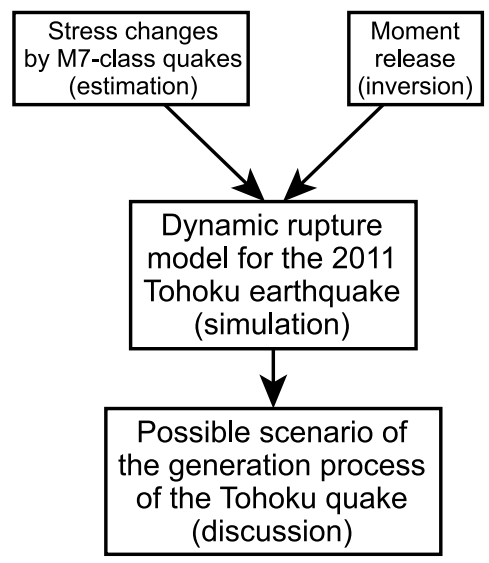

Fig. 1. The flow diagram of this study. We construct a dynamic rupture model, based on an estimation of the stress changes before the Tohoku earthquake and the moment-rate function of the Tohoku earthquake in previous studies (Yoshida et al., 2011; Iio and Matsuzawa, 2012). Then we discuss a possible scenario for the occurrence of the Tohoku earthquake.

been investigated by many researchers. We now have a qualitative common image of the rupture process, although the details have not yet been clarified. The rupture started from the hypocenter at approximately $38^{\circ} \mathrm{N}, 143^{\circ} \mathrm{E}$. In the first several seconds, the rupture behaved like an ordinary small earthquake (Chu et al., 2011), but it eventually propagated through a wide region of the subduction plate boundary east of northern Honshu. In many studies, the area of largest slip, which is as much as $50 \mathrm{~m}$ or more, was located to the east of the hypocenter, possibly near the Japan Trench (e.g., Fujii et al., 2011; Ide et al., 2011; Ito et al., 2011; Yagi and Fukahata, 2011). The slip around the hypocenter amounts to $20 \mathrm{~m}$ or more (e.g., Yagi and Fukahata, 2011; Yoshida et al., 2011), far greater than that of recent $M 7$ class earthquakes in this region.

In this paper, we consider why the Tohoku earthquake became a giant event and, in parallel, why previous earthquakes did not grow to the same extent. In terms of mechanics, we note that significant changes in the stress field due to the four $M$ 7-class earthquakes and their afterslip before the 2011 Tohoku earthquake (Fukushima-oki on October 31, 2003, Miyagi-oki on August 16, 2005, Fukushima-oki on July 19, 2008, and Miyagi-oki on March 9, 2011) caused stress accumulation around the hypocenter of the $M 9$ Tohoku earthquake (Iio et al., 2011; Iio and Matsuzawa, 2012). This stress concentration is likely to have affected rupture growth in the Tohoku earthquake, especially for the eastward rupture. In addition to this, many seismic inversion results (e.g., Ide et al., 2011; Yagi and Fukahata, 2011) suggest that seismic slip drastically increased after the arrival of the rupture in the near-trench area. The large slip in the near-trench area seems to have resulted in large horizontal extensional deformation within the overlying plate (Kato et al., 2011). We adopt a hypothesis that dynamically thermal pressurization of pore fluid (hereinafter called TP) in the fault zone played a key role in the release of stress (Mitsui et al., 2012).

To evaluate the effects of stress accumulation and TP quantitatively, we must use a three-dimensional mechani-
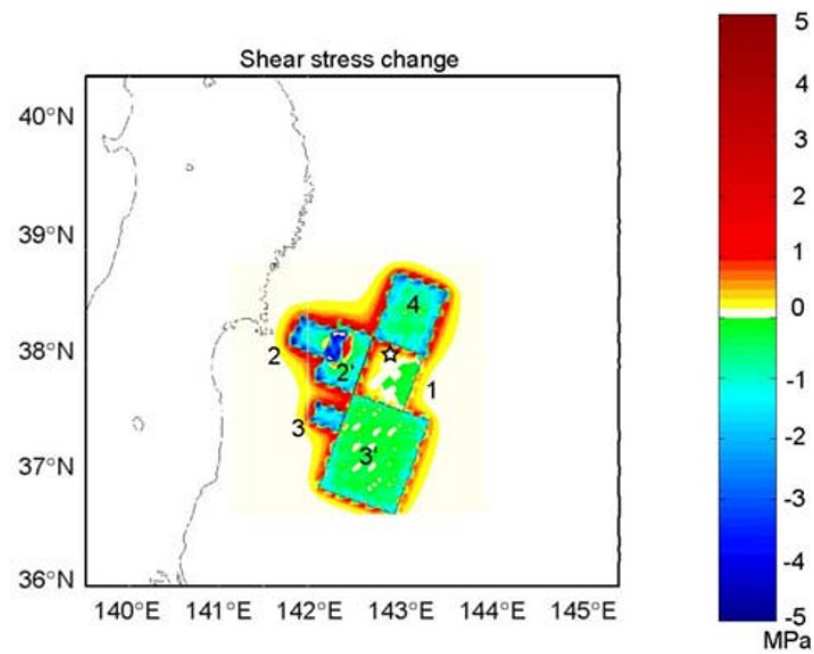

Fig. 2. Shear stress changes due to four $M$ 7-class earthquakes (Fukushima-Oki on October 31, 2003, Miyagi-Oki on August 16, 2005, Fukushima-Oki on July 19, 2008, and Miyagi-Oki on March 9, 2011) and their afterslip (Iio et al., 2011; Iio and Matsuzawa, 2012). The 2003 earthquake corresponds to the area of number 1, the 2005 earthquake corresponds to number 2 (coseismic slip) and $2^{\prime}$ (afterslip), the 2008 earthquake corresponds to number 3 (coseismic slip) and $3^{\prime}$ (afterslip), and the 2011 earthquake on March 9 corresponds to number 4 . The hypocenter of the 2011 Tohoku earthquake on March 11, located at $38.1^{\circ} \mathrm{N}, 142.86^{\circ} \mathrm{E}$ (determined by JMA) is shown by the star within the area of number 1 .

cal model for elastodynamic rupture propagation on a fault where friction changes with slip and pore pressure evolution. This experiment leads to a better understanding of the processes of the $M 9$ earthquake occurrence. Using the constructed simulation model, we are able to examine a possible scenario for the 2011 Tohoku earthquake and return to the initial questions of why the $M 9$ earthquake occurred on March 11, 2011, and why the previous earthquakes did not grow to the same extent.

Here, we show a dynamic rupture simulation with TP considering the stress accumulation before the 2011 Tohoku earthquake. To constrain many constitutive parameters, we refer to moment-rate functions of a seismic inversion study (Yoshida et al., 2011), which separately analyzed teleseismic waves and strong motion waves. After constructing the simulation model, we further examine the effects of stress changes due to the $M 7$-class earthquakes and discuss a possible scenario for the occurrence of the 2011 Tohoku earthquake. The flow diagram is illustrated in Fig. 1.

\section{Model and Method}

\subsection{Fault model}

Figure 2 shows the shear-stress changes due to the four M 7-class earthquakes (Fukushima-oki on October 31, 2003, Miyagi-oki on August 16, 2005, Fukushima-oki on July 19, 2008, Miyagi-oki on March 9, 2011) and their afterslip (Iio et al., 2011; Iio and Matsuzawa, 2012). The Fukushima-oki earthquake on October 31, 2003, had ruptured the area in which the hypocenter of the $M 9$ earthquake was located (Yamanaka and Kikuchi, 2004). The afterslip area of the Miyagi-oki earthquake on March 9, 2011, was not distinguished from its coseismic slip region. Such 


\section{Distance along dip [km]}

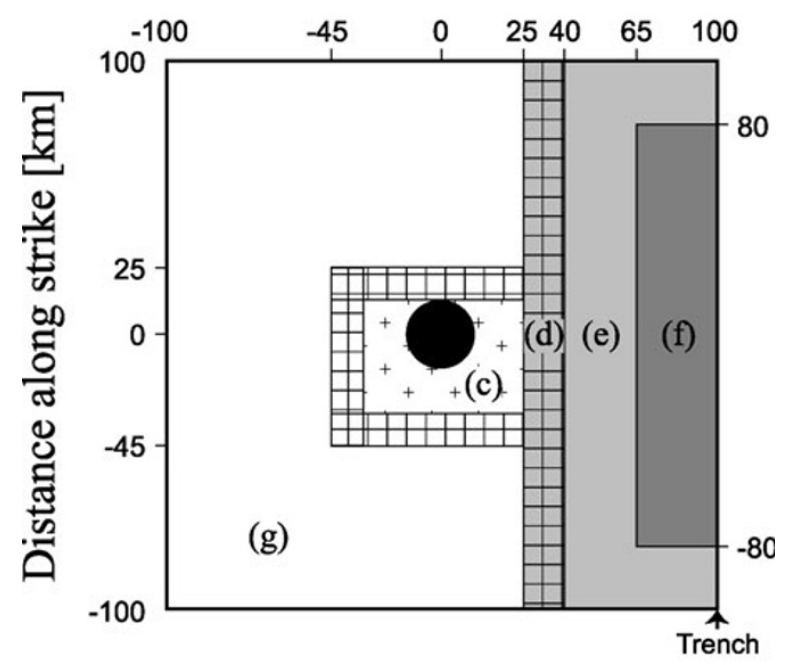

(a) Radius $12 \mathrm{~km} . \boxplus$ (b) Width $15 \mathrm{~km}$.

Fig. 3. The conceptual model fault for Model-1 and Model-2, divided into seven areas, (a)-(g). The earthquake rupture starts from area (a). We assume a different initial stress for areas (b) and (c) following the estimation of the stress accumulation around the hypocenter (Fig. 2). TP operates in both areas (b) and (c). With respect to near-trench areas (d)-(f), area (d) is set as a stress-accumulated region, and area (f) is assumed to be a region with efficient TP to release a large seismic moment.

stress heterogeneities induced by coseismic and postseismic slip of the $M$ 7-class earthquakes might be compensated for by long-term aseismic sliding on the plate interface. In this study, we assume that the stress fluctuations due to the $M 7$ class earthquakes from 2003 remained until 2011.

The shear stress on the plate interface were influenced on the order of MPa by the $M 7$-class earthquakes. In particular, we should note the increase in shear stress around the hypocenter of the Tohoku earthquake in four directions (Fig. 2). Such a situation had not been experienced in the previous 100 years, although stress accumulation in two directions occurred in the early 1980s in relation to two M 7-class earthquakes (Miyagi-oki on June 12, 1978, and Miyagi-oki on January 19, 1981). The four-direction stress increase is likely to be associated with the $M 9$ Tohoku earthquake.

Based on the above estimation, first we simply model the fault geometry of the 2011 Tohoku earthquake, including the source areas of the recent $M 7$-class earthquakes and their afterslip, as shown in Fig. 3. The coordinate origin of the model fault corresponds to the epicenter of the 2011 Tohoku earthquake, located at $38.1^{\circ} \mathrm{N}, 142.86^{\circ} \mathrm{E}$ (the value determined by JMA). The model fault is divided into seven areas, (a) $-(\mathrm{g})$. The earthquake rupture starts from area (a).

The size of this simplified fault is almost half of the actually ruptured fault. In particular, the southern edge of the simplified fault corresponds to the introduction of an artificial boundary. However, the simplified fault seems sufficient to model the important features of the earthquake occurrence because a large portion of the coseismic moment release in the Tohoku earthquake was concentrated on the northern half of the ruptured fault (e.g., Yoshida et al.,
2011). We first use this simplified fault model to construct a basic scenario, and then set a larger fault to perform more a realistic calculation (see Appendix).

\subsection{Frictional system and parameters}

For dynamic rupture simulations, we use a boundary integral equation method in the frequency domain (Geubelle and Rice, 1995; Day et al., 2005). The bulk elastic properties are as follows: the Poisson's ratio is 0.25 , the $S$-wave velocity $c_{s}$ is $3.3 \mathrm{~km} / \mathrm{s}$, and the rigidity $G$ is $30.5 \mathrm{GPa}$. Fault motion at each cell is controlled by the difference between loading stress $\tau_{\mathrm{lo}}$ and frictional strength $\tau_{\mathrm{fs}}$, obeying the equation of motion for a three-dimensional homogeneous elastic body. $\tau_{\mathrm{lo}}$ at each point changes due to slip at other points. In the conventional treatment, slipping points are distinguished from sticking points. When $\tau_{\mathrm{lo}}<\tau_{\mathrm{fs}}$, the slip velocity $v$ is fixed to be zero (sticking) and the shear stress $\tau_{\mathrm{sh}}$ is fixed to be equal to $\tau_{\mathrm{lo}}$. Once $\tau_{\mathrm{lo}}$ tends to exceed $\tau_{\mathrm{fs}}$, the slip velocity $v$ takes a positive value and $\tau_{\mathrm{sh}}$ is equal to $\tau_{\mathrm{fs}}$. As an initial condition on each fault cell, $\tau_{\mathrm{sh}}=\tau^{i}$ is set a priori. The distribution of $\tau^{i}$ used in the simulation is explained in the next subsection. To reduce computational costs, we fix the slip vector perpendicularly to the trench, because seismic inversion studies show that the Tohoku earthquake is basically a pure dip-slip event (e.g., Yagi and Fukahata, 2011).

We assume that the Coulomb friction $\tau_{\mathrm{fs}}=\mu(\sigma-p)$ on the fault, where $\mu$ is the frictional coefficient, $\sigma$ is the normal stress, and $p$ is the pore fluid pressure, evolves following two processes. One is the slip-dependent evolution of the frictional coefficient $\mu=\mu_{y}+F(D)$, where $\mu_{y}$ represents the normalized static strength and $D$ is the slip amount. $F(D)$ represents linear slip-weakening, simply given by $\left(\mu_{f}-\mu_{y}\right) D / D_{c}$ when $D<D_{c}$, and by $\mu_{f}-\mu_{y}$ when $D \geq D_{c}$ (Andrews, 1976a, b). $D_{c}$ is $3 \mathrm{~m}$ in this study. Note that the linear slip-weakening model is an idealization of many elementary physical processes (Andrews, 1976a), and may be too simple, as discussed in the literature (see the review by Bizzarri (2011a)). The other is the thermal pressurization of pore fluid (TP) via frictional heating, heat flow, and fluid flow, i.e., the law of energy conservation, the Fourier law, the law of mass conservation, and the Darcy law (Sibson, 1973; Lachenbruch, 1980; Mase and Smith, 1987; Bizzarri and Cocco, 2006). The latter process does not have a characteristic slip distance $D_{c}$ and a priori stress drop value, leading to continuous decrease of friction $\tau_{\mathrm{fs}}$ with slip $D$ (Lachenbruch, 1980; Abercrombie and Rice, 2005).

TP is composed of frictional heating, thermal diffusion, and fluid diffusion. In general, frictional heating with fault slip is accompanied by thermal diffusion and fluid diffusion. Since fluid diffusion parameters, such as permeability, vary by several orders of magnitude on faults (e.g., Tsutsumi et al., 2004), the effectiveness of TP is considered to be controlled mainly by fluid diffusion parameters (e.g., Lachenbruch, 1980). We need a suitable model for TP that can properly evaluate the above factors. The TP model in this study follows Bizzarri and Cocco (2006). Hereinafter, we assume a finite and constant thickness of the slip zone $w$, perfect conversion of internal energy into frictional heating, and an isotropic surrounding medium with a constant 
porosity. The pore pressure $p$ at time $t$ at a friction surface (the center of the slip zone) is given by

$$
\begin{array}{r}
p(t)=p_{0}+\frac{A}{w} \int_{0}^{t} d t^{\prime}\left[-\frac{\chi}{\varpi-\chi} \operatorname{erf}\left(\frac{w}{4 \sqrt{\chi\left(t-t^{\prime}\right)}}\right)\right. \\
\left.+\frac{\varpi}{\varpi-\chi} \operatorname{erf}\left(\frac{w}{4 \sqrt{\varpi\left(t-t^{\prime}\right)}}\right)\right] \\
\left.\cdot(\mu(\sigma-p) v)\right|_{t^{\prime}}
\end{array}
$$

where $p_{0}$ is a basal value of pore pressure, $\chi$ is the temperature diffusivity, $\varpi$ is the hydraulic diffusivity, and $A$ is a material parameter that incorporates the parameters of fluid thermal expansivity, fluid pressure compressibility, bulk density, and specific heat.

The basal effective normal stress $\sigma-p_{0}$ is assumed to be $40 \mathrm{MPa}$ over the whole fault. This assumption is based on a weak fault hypothesis at the subduction plate interface (e.g., Seno, 2009). The actual plate interface would have a more complex distribution of basal effective normal stress. In fact, a recent study (Zhao et al., 2011) revealed that the ruptured region in the Tohoku earthquake is inhomogeneous by seismic wave tomography (materials in the area subjected to large coseismic slip in the Tohoku earthquake are relatively stiff compared with the northern and southern area).

We set $w=0.04 \mathrm{~m}$ and $\chi=1.1 \times 10^{-6} \mathrm{~m}^{2} / \mathrm{s}$ as typical values for rocks (e.g., Noda and Shimamoto, 2005; Tanaka et al., 2007). We further assume $A=0.036$, which is on the small side as a typical value, leading to weaker effects of TP. The reason we assume weak TP will be described in a later section.

\subsection{Calculation set-ups}

Figure 3 shows the fault model used in the numerical simulation. We first describe conditions of the fault parameters in constructing the rupture simulation model.

In area (a) for rupture nucleation, the initial shear stress $\tau^{i}$ must slightly exceed the static strength $\mu_{y}\left(\sigma-p_{0}\right)$ to start dynamic rupture. The shape, size, and stress drop value for area (a) are set to enable outward rupture propagation (the energy release rate at the tip of area (a) must reach local fracture energy).

We assume identical frictional properties, but a different initial stress, for areas (b) and (c) following the estimation of the stress accumulation around the hypocenter (Fig. 2). We set a shear stress increase of 1.4 MPa in area (b), and no increase in area (c). Areas (b) and (c) roughly correspond to the ruptured area of the $M 7$-class earthquake on October 31, 2003 (ERI, 2003). Although we do not fully understand what caused the differences between the $M 7$ earthquake in 2003 and the $M 9$ earthquake in 2011, a nonlinear mechanism of frictional weakening might play an important role in rupture propagation in these areas. Thus, we assume an effective TP in areas (b) and (c).

In determining the frictional properties in areas (d)-(f), we cannot refer to previous $M 7$-class earthquakes. We are also unable to consult interseismic slip behavior because of the power lack of on-land GPS stations to constrain slip behavior at the plate interface (Loveless and Meade, 2011).
Table 1. The parameter distributions: the normalized initial shear stress $\tau^{i} /\left(\sigma-p_{0}\right)$, the normalized static strength $\mu_{y}$, the normalized residual strength $\mu_{f}$, and the hydraulic diffusivity $\varpi$. Area (s) is set only for Model-3.

\begin{tabular}{ccccc}
\hline Area & $\tau^{i} /\left(\sigma-p_{0}\right)$ & $\mu_{y}$ & $\mu_{f}$ & $\varpi\left[\mathrm{m}^{2} / \mathrm{s}\right]$ \\
\hline (a) & 0.57 & 0.57 & 0.32 & - \\
(b) & 0.605 & 0.65 & 0.57 & $7.0 \times 10^{-3}$ \\
(c) & 0.57 & 0.65 & 0.57 & $7.0 \times 10^{-3}$ \\
(d) & 0.615 & 0.65 & 0.645 & - \\
(e) & 0.58 & 0.65 & 0.645 & - \\
(f) & 0.58 & 0.65 & 0.645 & $4.7 \times 10^{-4}$ \\
(g) & 0.54 & 0.56 & 0.54 & - \\
(s) & 0.605 & 0.65 & 0.52 & - \\
\hline
\end{tabular}

The constraint on these areas is the coseismic moment release for the Tohoku earthquake, estimated from slip inversions. Among areas (d)-(f), area (d) is a stress-accumulated region like area (b). We assume that TP operates effectively in area (f) to cause an extremely large slip after the rupture reaches there.

For area $(\mathrm{g})$, we set the initial stress $\tau^{i}$ to be the same as the residual strength $\mu_{f}\left(\sigma-p_{0}\right)$. This assumption is not strange since the source areas of the recent $M 7$-class earthquakes must have had low stress and static strength. The assumption of the same level of $\tau^{i} /\left(\sigma-p_{0}\right)$ and $\mu_{f}$ also corresponds to a conditional stability in terms of a rateand state-dependent friction (Ruina, 1983; Boatwright and Cocco, 1996), which might be adequate for the non-source areas of the $M$ 7-class earthquakes (Mitsui and Iio, 2011).

The boundary conditions at the edges of the model fault are fixed ends, except at the east edge. For the east edge, to represent the effect of the free surface at the Japan Trench, we assume a free end condition by using a mirror method about the displacement vector to eliminate strain.

After much trial and error to assimilate the moment release rate in the seismic inversion (Yoshida et al., 2011) under the above-mentioned constraints, a set of frictional parameters in the model fault (Fig. 3) are chosen as Model1. The parameters for Model-1 are shown in Table 1.

Next, we use another parameter set for Model-2, to evaluate the effects of the initial stress. Model-1 and Model-2 have the same frictional properties, including hydraulic parameters, but they have different initial conditions in terms of normalized shear stress $\tau^{i} /\left(\sigma-p_{0}\right)$ as illustrated in Fig. 4. Model-2 reflects only the northern and western parts of the stress concentration in Model-1. This model roughly simulates the conditions after the two $M 7$-class earthquakes occurred off Miyagi on June 12, 1978, and January 19, 1981, although the stress accumulation in the northern part due to the 1981 earthquake was probably smaller than that due to the March 9, 2011, earthquake, because of the smaller fault slip in the 1981 earthquake (Yamanaka and Kikuchi, 2004).

To solve the nonlinear equation system, we first use a second-order Runge-Kutta algorithm to obtain the evolution of $v$ and $\tau_{\mathrm{lo}}$ and to obtain a value for $p$ from Eq. (1). Then, in the next time step, using the obtained values, all of the variables are calculated again. The calculation process continues until seismic slip is halted in the whole model 
(i)

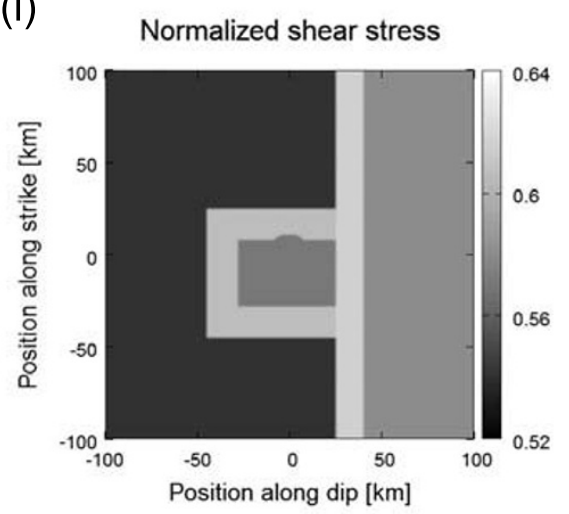

(ii)

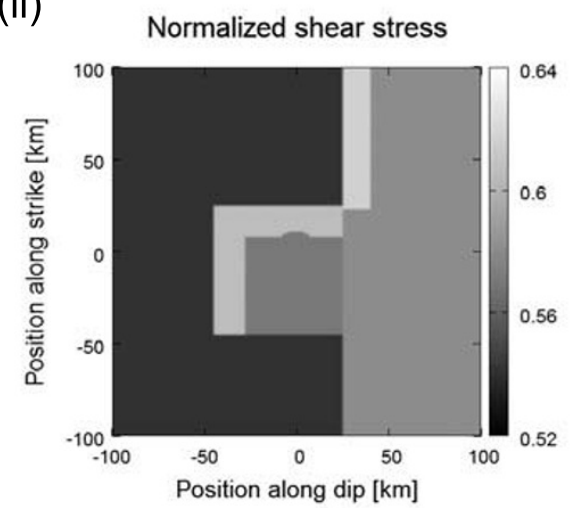

Fig. 4. Initial conditions of the normalized shear stress $\tau^{i} /\left(\sigma-p_{0}\right)$ for Model-1 and Model-2. Model-2 reflects only the northern and western parts of the stress concentration of Model-1, which simulates the conditions just after two $M 7$-class earthquakes off Miyagi (on June 12, 1978 and January 19, 1981).

region.

The actual calculation field is more than ten times larger than the model fault shown in Fig. 3. Since the boundary integral equation method in the frequency domain leads to periodic conditions in the actual calculation field, the model fault must be sufficiently smaller than the calculation field. The fault plane is divided into equal-sized cells $(1 \mathrm{~km} \times$ $1 \mathrm{~km})$. The numerical time step is set to $0.1 \mathrm{~km}$ divided by the $P$-wave velocity. Using these values, and the model parameters, we check the values of critical numerical cell sizes that are determined by elastic stiffness and the gradient of the slip-weakening curve for each cell. A critical cell size for discretization $\Delta x^{*}$ for the linear slip-weakening friction is given (Bizzarri and Cocco, 2005) by

$$
\Delta x^{*}=\frac{G \Delta x D_{c}}{c_{s} \Delta t\left(\mu_{y}-\mu_{f}\right)\left(\sigma-p_{0}\right)},
$$

where $\Delta x$ is the numerical cell size and $\Delta t$ is the numerical time step. This critical value is related to the CFL condition (Fukuyama and Madariaga, 1998; Bizzarri and Cocco, 2005). We confirm that the minimal value of $\Delta x^{*}$ is around $150 \mathrm{~km}$, which is two-orders larger than $\Delta x$. This fact ensures numerical stabilities for the linear slip-weakening part.

\section{Results}

Figure 5 illustrates the evolution of coseismic slip for Model-1. The earthquake first ruptures in the nearhypocenter area over $30 \mathrm{~s}$ with a large slip of the order of $15 \mathrm{~m}$. Then the eastward slow rupture reaches area (f) and causes an extremely large slip near the trench, as a result of an efficient TP. The large slip in area (f) leads to the propagation of the second rupture over the fault. The propagation of the second rupture is fast in the previously ruptured area.

Figure 6 exhibits the calculated final slip distribution and moment release rate in comparison with the moment-rate function obtained by the slip inversion analyses of teleseismic and strong-motion data (Yoshida et al., 2011). During the initial $10 \mathrm{~s}$, the calculation does not reproduce well the inversion results. The difference derives from the choices of the parameters for the initial nucleation, e.g., nucleation size, stress drop, and characteristic slip-weakening distance $D_{c}$. We possibly need to take into account smaller-scale heterogeneity (Aochi and Ide, 2004) in our rupture simulation of the initial part. The calculation result traces well the inversion in the following 10-30 s, which corresponds to the seismic slip around the hypocenter. During the period 30-45 s, the calculated moment release rate falls below the inversion results. It may imply the existence of another slip patch located in a deeper region (e.g., Ide et al., 2011; Iinuma et al., 2011; Meng et al., 2011), part of which will be considered in the following model with a larger fault (Model-3 described in Appendix). Afterwards, the effective TP near the trench causes a drastic moment release, although it does not yet reach the inversion results. The final moment magnitude is 8.9 in Model-1.

We further focus on the local evolution of slip velocity and stress on the fault. Figure 7(i) shows the locations of targeted points, P1 in area (c) and P2 in area (f). The evolution of the slip velocity $v$ and the effective normal stress $\sigma-p$ at $\mathrm{P} 1$ and $\mathrm{P} 2$ are presented in Fig. 7(ii). When the slip velocity $v$ has a positive value, the effective normal stress $\sigma-p$ decreases due to the TP effect. After the finish of slip, the effective normal stress tends to be rapidly restored via fluid diffusion.

Figure 7(iii) presents the evolution of the frictional strength $\tau_{\mathrm{fs}}$, the loading stress $\tau_{\mathrm{lo}}$, and the shear stress $\tau_{\mathrm{sh}}$ at P2; the meanings of the parameters were described in Section 2.2. At the moment when $\tau_{\mathrm{lo}}=\tau_{\mathrm{sh}}$ exceeds $\tau_{\mathrm{fs}}$, the fault starts to slip. During the fault slip, $\tau_{\mathrm{sh}}$ is equal to $\tau_{\mathrm{fs}}$. For instance, to discuss stress histories on the fault, we should refer to the values of $\tau_{\mathrm{sh}}$. The simulation result in Fig. 7(iii) shows a local dynamic undershoot $\left(\tau_{\mathrm{sh}}\right.$ increases after the finish of the fault slip). This tendency corresponds to an earlier result presented by Mitsui and Hirahara (2009), although their fault model with one-degree-of-freedom was rather simpler than that in this study. (Note that the definitions of the parameters are confusing. " $\tau$ " and " $\tau_{f}$ " in Mitsui and Hirahara (2009) respectively correspond to $\tau_{\mathrm{lo}}$ and $\tau_{\mathrm{sh}}$ in this study. Since the fault system with the rateand state-dependent friction of Mitsui and Hirahara (2009) does not stop slipping, $\tau_{\mathrm{fs}}$ does not appear explicitly in their 
(i) $10 \mathrm{~s}$

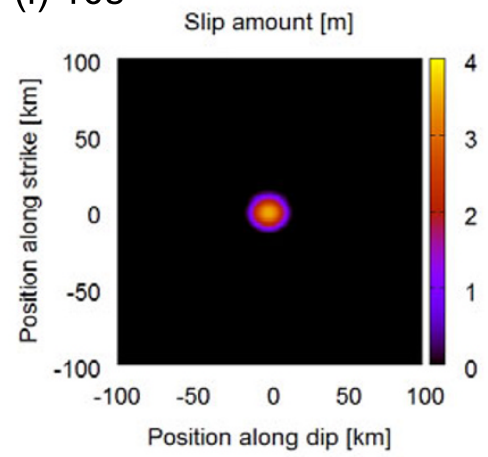

(iv) $40 \mathrm{~s}$

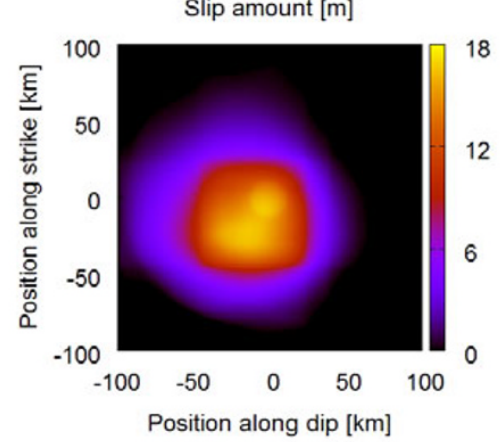

(ii) $20 \mathrm{~s}$

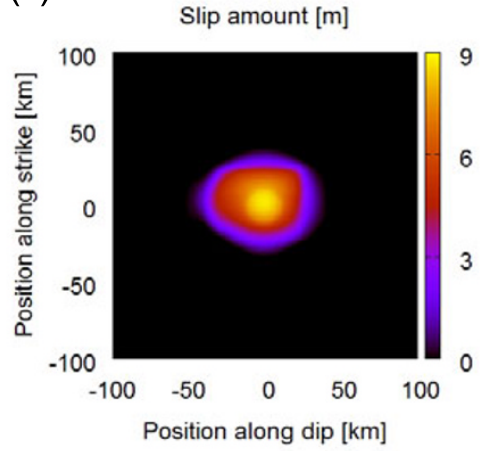

(v) $50 \mathrm{~s}$

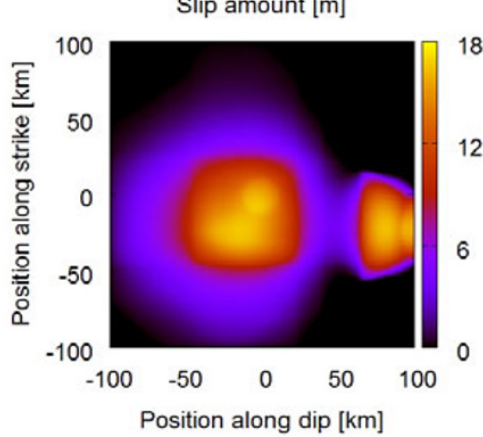

(iii) $30 \mathrm{~s}$

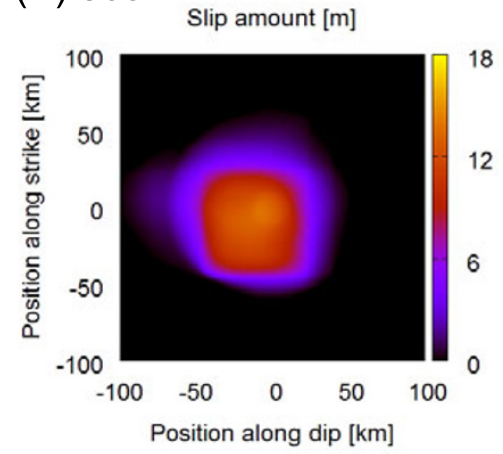

(vi) final

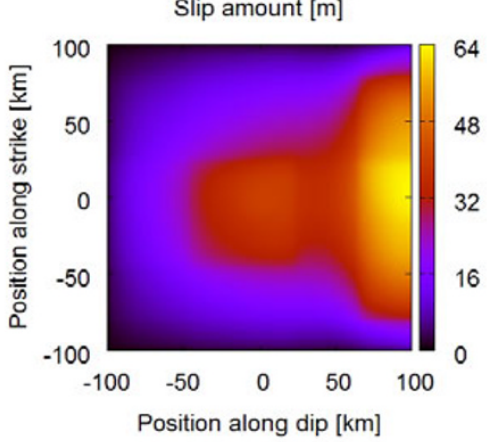

Fig. 5. The evolution of coseismic slip for Model-1. Note that the color scale in each figure is not the same. (i) Snapshot at $10 \mathrm{~s}$ after the rupture start. (ii) At 20 s. (iii) At 30 s. (iv) At 40 s. (v) At 50 s. (vi) Final slip distribution.
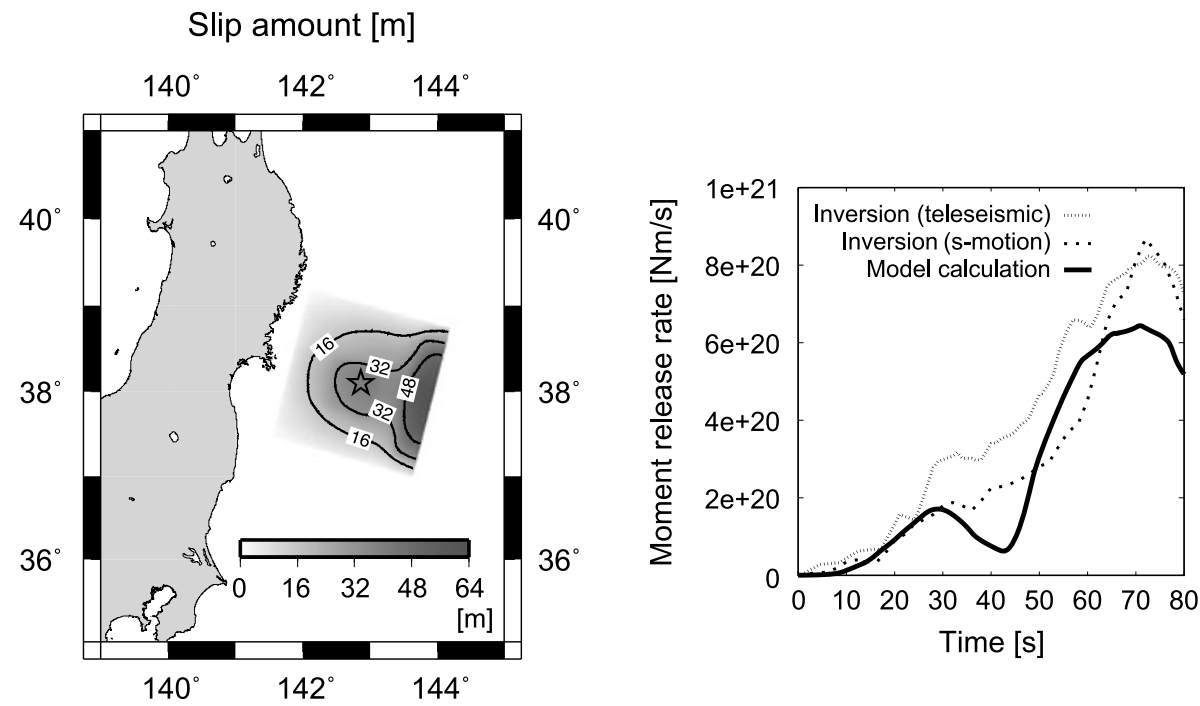

Fig. 6. Calculated final slip distribution and moment release rate for Model-1 in comparison with the moment-rate function in the slip inversion result (Yoshida et al., 2011). We assume that the dip angle of the plate interface is $20^{\circ}$, and the epicenter of the 2011 Tohoku earthquake is located at $38.1^{\circ} \mathrm{N}, 143.86^{\circ} \mathrm{E}$ (the value determined by JMA).

system.)

The equation system in our calculation includes the temporal convolution with respect to the dynamic elastic interaction (Day et al., 2005), and the temperature and pore pressure evolution (Eq. (1)). Because of the limitation of computer memory, we cannot store all the computed data. The simulation result generally depends on the numerical time step, but we do not have analytical solutions to assess the accuracy for the non-linear friction evolution of TP. In order to check the computed results, we perform a simulation with the same setting as in Model-1, but the length of time step is doubled. In Fig. 8, we compare the moment release calculated with the original time step (thick line) and the double-length time step (thin line). The moment release curves are similar, although there is a slight difference especially during the rupture period in the near-trench TP region. The final moments are also almost the same. This result indicates that our calculations have sufficient numer- 
(i)

$$
\text { (i) Distance along } \operatorname{dip}[\mathrm{km}]
$$

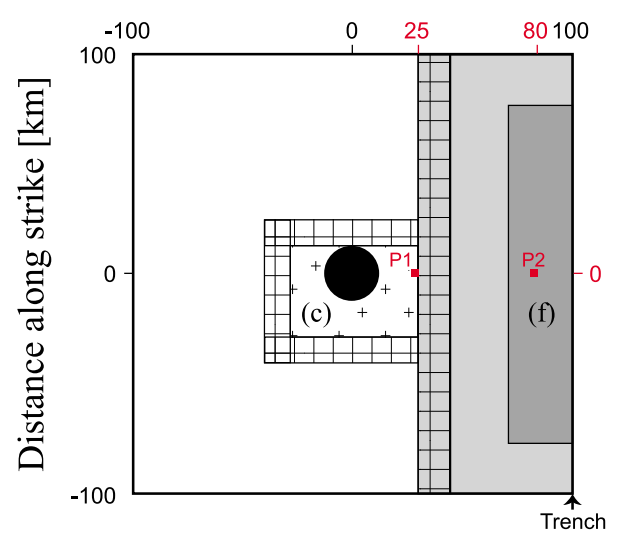

(ii)

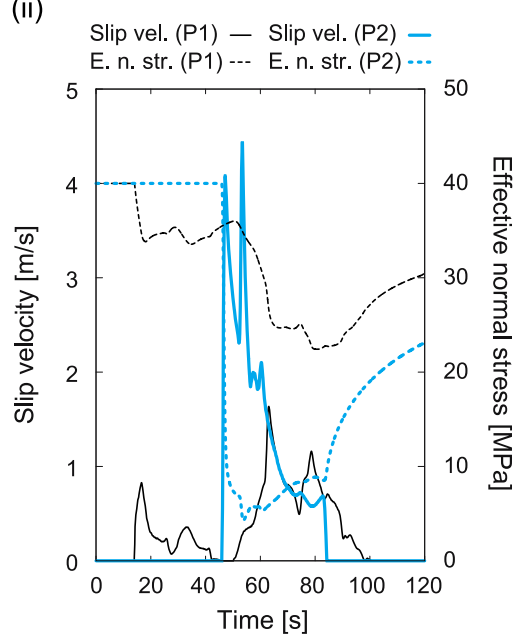

(iii)

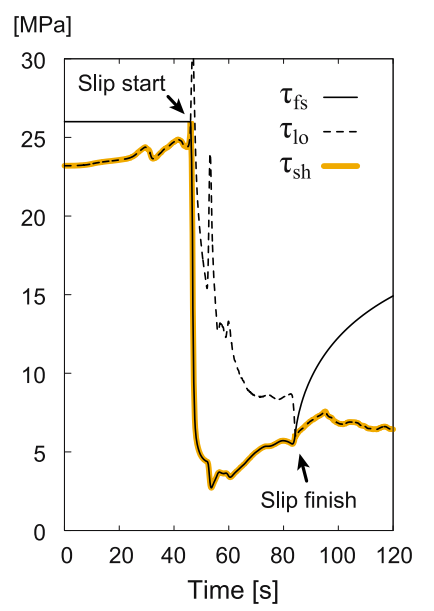

Fig. 7. (i) Locations of point 1 (P1) and point $2(\mathrm{P} 2)$ on the fault. (ii) Evolution of the slip velocity $v$ and the effective normal stress $\sigma-p$ at $\mathrm{P} 1$ and $\mathrm{P} 2$. (iii) Evolution of the frictional strength $\tau_{\mathrm{fs}}$, the loading stress $\tau_{\mathrm{lo}}$, and the shear stress $\tau_{\mathrm{sh}}$ at $\mathrm{P} 2$.

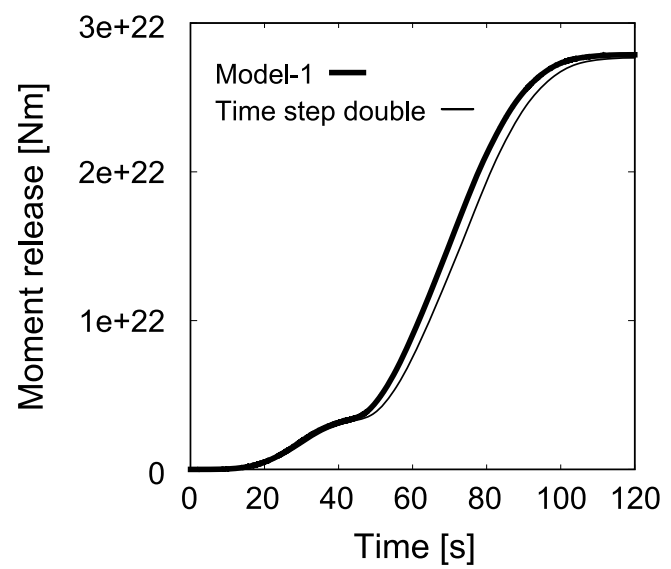

Fig. 8. Verification of numerical accuracy: moment release in case of Model-1 and the model with doubled time step.

ical accuracy to allow us to discuss the rupture process.

In order to investigate the effects of the stress accumulation caused by the $M 7$-class earthquakes, we then set Model-2 that only considers the northern and western parts of the stress concentration in Model-1 (Fig. 4).

Figure 9 shows the final slip distribution and the momentrate function for Model-2. Since the seismic rupture does not reach the near-trench TP region, the moment-rate function decays around $50 \mathrm{~s}$, which exhibits a clear contrast to Model-1. Figure 10 illustrates the evolution of the slip velocity and effective normal stress at P1 around the hypocenter (see Fig. 7(i)) to show the difference between Model-1 and Model-2. In the case of Model-2, the slip velocity is totally slower and the effective normal stress during the slip is larger than in Model-1. The final moment magnitude for Model-2 is 8.2. This means that the $M 9$ earthquake ends up as an $M 8$-class earthquake without sufficient stress concentration. The stress changes via the recent four $M 7$-class earthquakes seem to have played an essential role in the occurrence of the 2011 Tohoku earthquake.

\section{Discussion}

\subsection{Role of dynamic weakening}

By comparing Model-1 with Model-2, we illuminated the notable role of the initial stress conditions on the growth of earthquakes ( $M 8$-class or $M 9$-class), in which triggering the extremely large slip owing to TP holds the key. Parametric experiments with a simpler setting of the model fault (Fukahata et al., 2012) also show that the stress field before the earthquake controls the rupture propagation in the area between the hypocenter and the trench. It should be noted that a four-direction stress accumulation occurred before the Tohoku earthquake, whereas only a two-direction, or smaller, stress increase had occurred in the case of the previous $M 7$-class earthquakes, at least in the last one hundred years. This study suggests that a rare condition of the stress field, as well as TP, near the trench may be necessary for the occurrence of $M 9$ earthquakes in this region. The hydraulic parameters for TP may also change in time. Acute sensitivity to initial stress conditions, prescribed by local seismic activities and changeable TP parameters, raise a question about the concept of (quasi-)cyclic occurrences of M 9 earthquakes, as discussed in Yagi and Fukahata (2011).

The dynamic-weakening hypothesis is further reinforced by observations of many normal-fault-type aftershocks (e.g., Asano et al., 2011), which imply that the absolute stress in this region was almost completely released by the Tohoku earthquake (e.g., Hasegawa et al., 2011). It is notable that the fault-slip models utilizing the rate- and statedependent friction law (e.g., Hori and Miyazaki, 2011; Kato and Yoshida, 2011) do not explain such phenomena, since they do not include the effects of absolute stress level. TP is probably a dominant physical mechanism of dynamic weakening causing the release of absolute stress in such a wide region, since frictional melting, which is another popular dynamic-weakening mechanism, may act as an opposite dynamic-strengthening mechanism due to viscous braking in shallow zones (e.g., Otsuki et al., 2003; Ujiie et al., 2009).

If the extremely large slip of the Tohoku earthquake in the shallow part is associated with dynamic fault weakening, as 

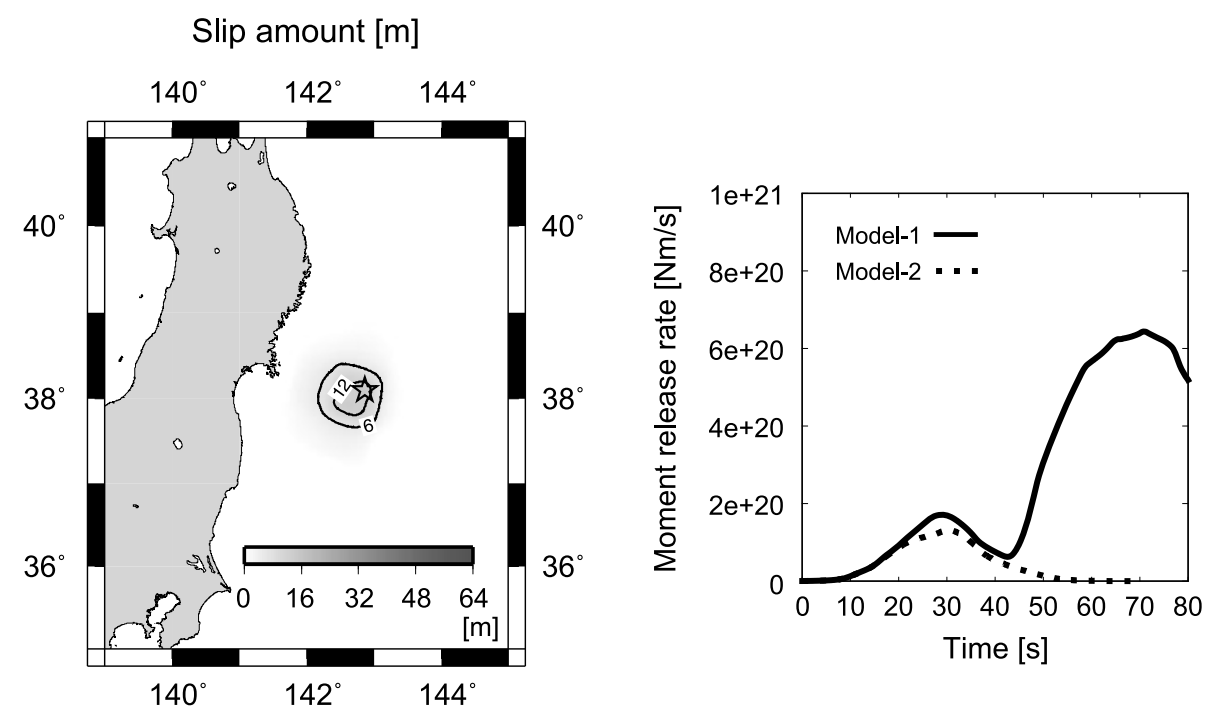

Fig. 9. Calculated final slip distribution for Model-2 and moment release rate for Model-2 in comparison with Model-1.

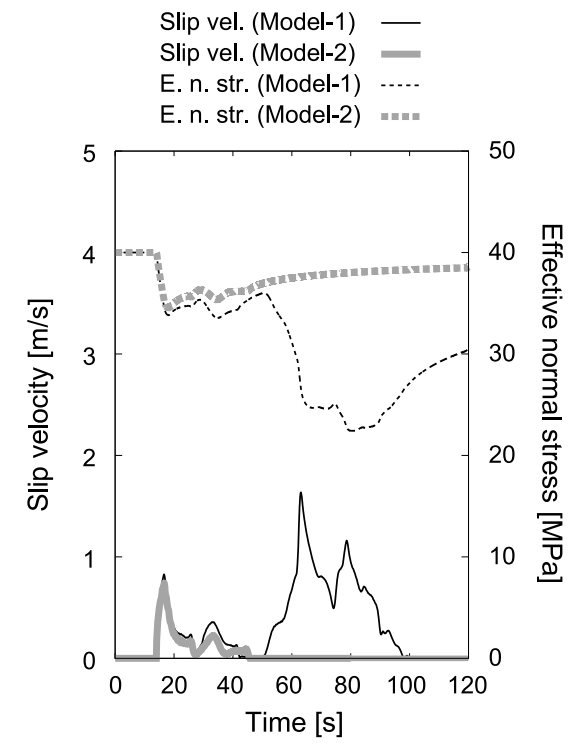

Fig. 10. Evolution of the slip velocity $v$ and the effective normal stress $\sigma-p$ at P1 (see Fig. 7(i)) for Model-1 and Model-2.

demonstrated in this study, a strongly locked area during interseismic periods is not necessarily needed for the occurrence of megaquakes. In fact, an observation study (Tohoku University, 2010) suggested the occurrence of a slow earthquake in 2008, whose source region was located within the large slip area of the Tohoku earthquake. This finding may indicate that the fault in the whole shallow part had not been strongly locked in an interseismic phase.

\subsection{Effective but moderate TP}

As indicated in Section 2.2, we set $A=0.036$ as a parameter for TP, which is on the small side within the typical range, because an effective, but moderate, TP is needed to assimilate the moment release rate in the seismic inversions. If the effect of TP is stronger, the moment release in the near-trench region grows too fast. A small $A$ is not the only way to restrain the TP effect in numerical calculations. Primarily, the specific amount of the moment release depends on the assumed area for TP; there is a trade-off between the degree of TP and the dimensions of the TP region. The degree of $\mathrm{TP}$ also depends on the absolute stress level: for instance, the basal effective normal stress $\sigma-p_{0}$. Next, as several numerical studies (e.g., Suzuki and Yamashita, 2007; Mitsui and Cocco, 2010; Bizzarri, 2012) have mentioned, pore pressure decrease owing to pore dilatation could counteract TP efficiently. In this context, one study (Mitsui and Cocco, 2010) proposed that more frictionally unstable systems lead to a more effective counteraction of porosity evolution to the TP effect. This result corresponds to our assumption of the existence of an interseismically stable (not strongly locked) region near the trench, part of which is the TP region. However, since the restraining effect strongly depends on the constitutive law of porosity evolution, this issue is still under debate. More experimental support, such as that provided by Tanikawa et al. (2010), is necessary to clarify this problem. Lastly, the effect of offfault plastic yielding can restrain the dynamic-weakening effect (e.g., Andrews, 2005; Dunham et al., 2011). By contrast, the effect of material contrast across the fault (e.g., Ben-Zion, 2001; Ma and Beroza, 2008) may not counteract the dynamic-weakening effect in this case, since a hanging wall in a subduction fault is considered to be more compliant than a footwall.

Of course, the results in this study also depend on the evolution of the frictional coefficient. The linear slipweakening law assumed in this study might be responsible for the moderate TP hypothesis. For example, we found that the temperature on the model fault could exceed a typical melting temperature $\left(1200^{\circ} \mathrm{C}\right)$ transiently, although the amount of the temperature increase strongly depends on the assumed absolute stress level. The melting of rock leads to viscous rheology, not the Coulomb friction (e.g., Nielsen et al., 2008; Bizzarri, 2011b). Such complicated rheology should be implemented to represent actual fault behavior more precisely. 


\section{Conclusion}

We constructed a fault model for the dynamic rupture simulation of the 2011 Tohoku earthquake. The model included the dynamic weakening mechanism of TP. It also reflected the estimation of the shear stress changes before the Tohoku earthquake, due to the four $M 7$-class earthquakes which occurred during 2003-2011.

Based on the model, we succeeded in simulating the rupture process of the Tohoku earthquake, to some extent, by assimilating the moment-rate function in the seismic slip inversions, and proposed a possible scenario for its generation process, as follows. The rupture around the hypocenter was enhanced by the stress accumulation due to the four $M 7$-class earthquakes. The enhanced rupture triggered the TP mechanism in the near-trench area resulting in an extremely large slip. The near-trench effective TP, which should be effective but moderate, did not operate during the initial $40 \mathrm{~s}$. The rupture was further promoted by the neartrench TP to propagate across a wide region, including the source areas of the $M 7$-class earthquakes and a surrounding conditionally-stable area. If the stress concentration around the hypocenter was insufficient, the Tohoku earthquake could end as an $M$ 8-class earthquake. The TP effect around the hypocenter area might play a major role in this process. The nonlinear effects of TP and the stress conditions on the earthquake magnitude would lead to a greatly fluctuating occurrence time of following large earthquakes. Thus, our model implies that the concept of (quasi-)cyclic earthquake occurrences may not be applicable to $M 9$ earthquakes in this region.

Acknowledgments. We thank Yasuhiro Yoshida and Hiroshi Ueno for providing us with the results of their seismic inversions. We also thank Masao Nakatani, Takeshi Tsuji, Hiroyuki Goto, Kazuro Hirahara and Naoyuki Kato for comments and discussions. We used the Generic Mapping Tools (Wessel and Smith, 1995) to draw the figures.

\section{Appendix A. Model-3 (Larger Fault Model)}

Model-1 and Model-2 were based on a simplified conceptual fault model (Fig. 3). As shown in Fig. 2, the shearstress changes due to the previous $M 7$-class earthquakes were more complex than those included in Model-1 and Model-2. Furthermore, the actual area of the ruptured fault is estimated to be larger than that of Model-1 and Model-2 (200 km quadrate), especially toward the south (e.g., Honda et al., 2011; Yao et al., 2011). Indeed, the rupture in Model1 is restrained by the artificial fault boundaries. We thus construct a more "realistic" model with a larger fault.

Figure A.1 shows the larger fault model $(250 \mathrm{~km} \times$ $400 \mathrm{~km}$ ), where areas (d), (e), and (g) are enlarged, but the parameters for the frictional properties in areas (a)-(g) (Table 1) remain unchanged from Model-1. Furthermore, area (s) is added to represent the zones of increased stress due to the $M 7$-class earthquakes (see Fig. 2). Area (s) has a higher static strength than area (g), because coseismic and postseismic slip of the $M 7$-class earthquakes were arrested in area (s). We thus set the normalized initial shear stress $\tau^{i} /\left(\sigma-p_{0}\right)=0.605$, the normalized static strength $\mu_{y}=0.65$ and the normalized residual strength $\mu_{f}=0.52$.

Figure A.2 presents the calculation results for Model-3.

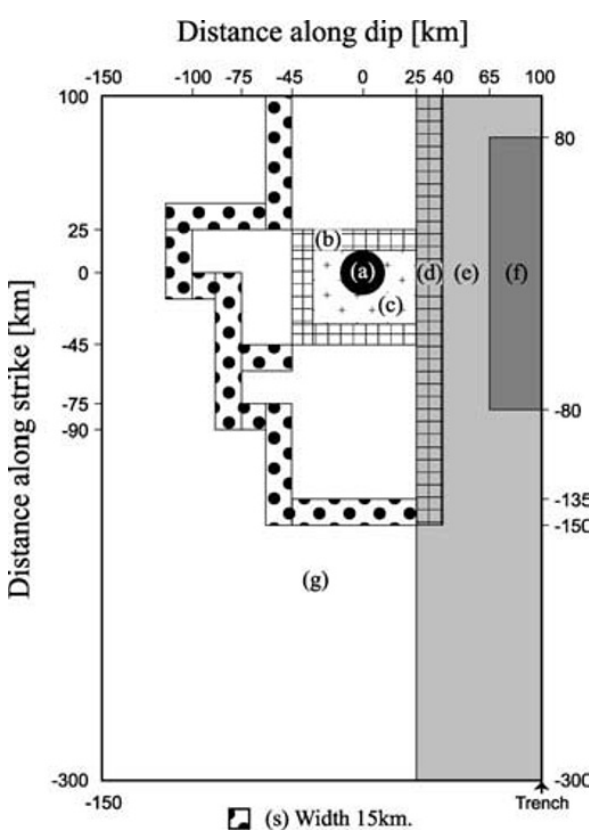

Fig. A.1. A conceptual model fault for a larger fault model (Model-3), divided into eight areas (a)-(g) and area (s). Areas (d), (e), and (g) are extended from Model-1 and Model-2 (Fig. 4), and area (s) is added to represent the zones with the increased stress due to the $M 7$-class earthquakes (see Fig. 2). Area (s) has a higher static strength than area $(\mathrm{g})$, because the coseismic and postseismic slip of the $M 7$-class earthquakes had stopped at area (s).
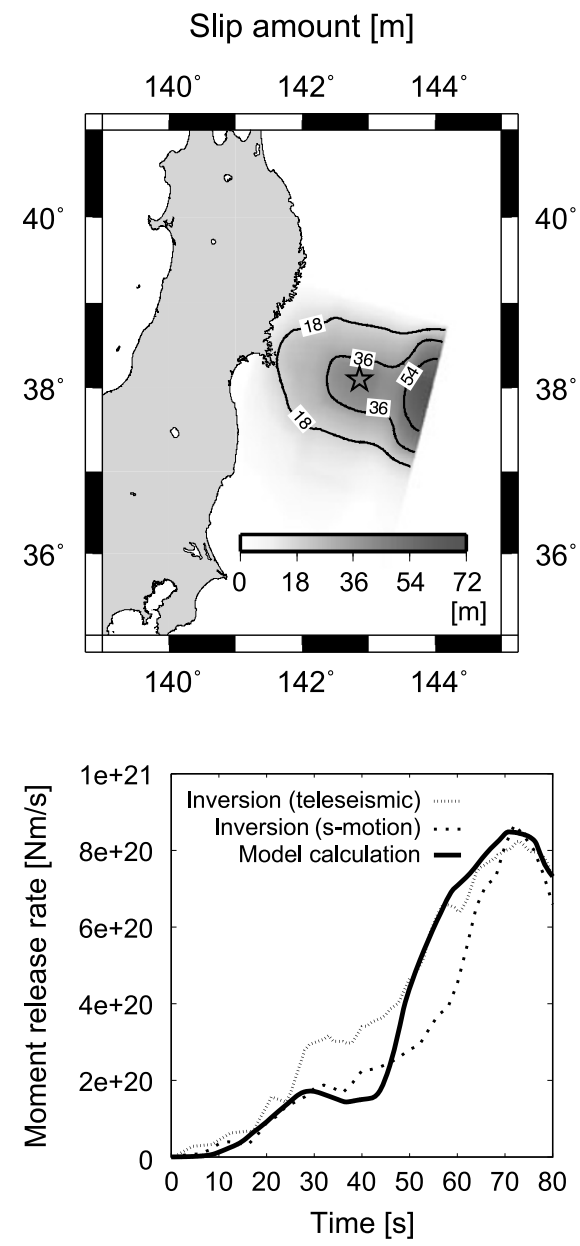

Fig. A.2. Calculated final slip distribution for Model-3 and moment release rate for Model-3. 
The calculated moment release rate corresponds better to the inversion values, by enlarging the model fault. The final moment magnitude is 9.0. The seismic rupture does not reach the southern end of the fault (around $36^{\circ} \mathrm{N}$ latitude), but the slip amount in the southern part is not so small (e.g., approximately $10 \mathrm{~m}$ at $37^{\circ} \mathrm{N}, 142^{\circ} \mathrm{E}$ ) compared with previous $M 7$-class earthquakes.

In the light of earthquake scaling, we checked the radiation efficiency, which is defined as the radiation energy from the whole fault divided by the seismic moment. The radiation efficiency is almost $9 \times 10^{-5}$. This value is within the range of an earthquake scaling that is valid over 17 orders of seismic moment (Ide and Beroza, 2001).

Model-3 is more realistic than Model-1. However, in terms of the scenario for the occurrence of the Tohoku earthquake, Model-1 is sufficient to represent the key points (importance of the stress concentration around the hypocenter).

\section{References}

Abercrombie, R. E. and J. R. Rice, Can observations of earthquake scaling constrain slip weakening?, Geophys. J. Int., 162, 406-424, 2005.

Andrews, D. J., Rupture propagation with finite stress in antiplane strain, J. Geophys. Res., 81, 3575-3582, 1976a.

Andrews, D. J., Rupture velocity of plane strain shear cracks, J. Geophys. Res., 81, 5679-5687, 1976b.

Andrews, D. J., Rupture dynamics with energy loss outside the slip zone, J. Geophys. Res., 110(B01307), doi:10.1029/2004JB003191, 2005.

Aochi, H. and S. Ide, Numerical study on multi-scaling earthquake rupture, Geophys. Res. Lett., 31, doi:10.1029/2003GL018708, 2004.

Asano, Y., T. Saito, Y. Ito, K. Shiomi, H. Hirose, T. Matsumoto, S. Aoi, S. Hori, and S. Sekiguchi, Spatial distribution and focal mechanisms of aftershocks of the 2011 off the Pacific coast of Tohoku Earthquake, Earth Planets Space, 63, 669-673, 2011.

Ben-Zion, Y., Dynamic ruptures in recent models of earthquake faults, Rev. Geophys., 49, 2209-2244, 2001.

Bizzarri, A., On the deterministic description of earthquakes, Rev. Geophys., 49, doi:10.1029/2011RG000356, 2011a.

Bizzarri, A., Dynamic seismic ruptures on melting fault zones, J. Geophys. Res., 116, doi:10.1029/2010JB007724, 2011b.

Bizzarri, A., Effects of permeability and porosity evolution on simulated earthquakes, J. Struct. Geol., doi:10.1016/j.jsg.2011.07.009., in press.

Bizzarri, A. and M. Cocco, 3D dynamic simulations of spontaneous rupture propagation governed by different constitutive laws with rake rotation allowed, Ann. Geophys., 48(2), 279-299, 2005.

Bizzarri, A. and M. Cocco, A thermal pressurization model for the spontaneous dynamic rupture propagation on a three-dimensional fault: 1. Methodological approach, J. Geophys. Res., 111, B05303, doi:10.1029/2005JB003862, 2006.

Boatwright, J. and M. Cocco, Frictional constraints on crustal faulting, $J$. Geophys. Res., 101(B6), 13895-13909, 1996.

Chu, R., S. Wei, D. V. Helmberger, Z. Zhan, L. Zhu, and H. Kanamori, Initiation of the great Mw 9.0 Tohoku-Oki earthquake, Earth Planet. Sci. Lett., 308, 277-283, 2011.

Day, S. M., L. A. Dalguer, N. Lapusta, and Y. Liu, Comparison of finite difference and boundary integral solutions to three-dimensional spontaneous rupture, J. Geophys. Res., 110(B12), doi:10.1029/2005JB003813, 2005.

Dunham, E. M., D. Belanger, L. Cong, and J. E. Kozdon, Earthquake ruptures with strongly rate-weakening friction and off-fault plasticity, part 1: Planar faults, Bull. Seismol. Soc. Am., 101(5), 2296-2307, 2011.

ERI, EIC seismology note (No.141), http://www.eri.u-tokyo.ac.jp/ sanchu/Seismo_Note/EIC_News/031031.html, 2003.

Fujii, Y., K. Satake, S. Sakai, M. Shinohara, and T. Kanazawa, Tsunami source of the 2011 off the Pacific coast of Tohoku Earthquake, Earth Planets Space, 63, 815-820, 2011.

Fukahata, Y., Y. Yagi, and Y. Mitsui, Absolute strain release in the 2011 Tohoku-oki Earthquake: Waveform inversion and dynamic fault weakening, J. Geol. Soc. Jpn., 118(7), 396-409, 2012 (in Japanese with English abstract).
Fukuyama, E. and R. Madariaga, Rupture dynamics of a planar fault in a 3D elastic medium: Rate- and slip-weakening friction, Bull. Seismol. Soc. Am., 88, 1-17, 1998.

Geubelle, P. and J. R. Rice, A spectral method for three-dimensional elastodynamic fracture problems, J. Mech. Phys. Solids, 43(11), 1791-1824, 1995

Hasegawa, A., K. Yoshida, and T. Okada, Nearly complete stress drop in the $2011 M_{\mathrm{w}} 9.0$ off the Pacific coast of Tohoku Earthquake, Earth Planets Space, 63, 703-707, 2011.

Hashimoto, C., A. Noda, T. Sagiya, and M. Matsu'ura, Interplate seismogenic zones along the Kuril-Japan trench inferred from GPS data inversion, Nat. Geosci., 2, 141-144, 2009.

Honda, R., Y. Yukutake, H. Ito, M. Harada, T. Aketagawa, A. Yoshida, S. Sakai, S. Nakagawa, N. Hirata, K. Obara, and H. Kimura, A complex rupture image of the 2011 off the Pacific coast of Tohoku Earthquake revealed by the MeSO-net, Earth Planets Space, 63, 583-588, 2011.

Hori, T. and S. Miyazaki, A possible mechanism of $M 9$ earthquake generation cycles in the area of repeating $M 7 \sim 8$ earthquakes surrounded by aseismic sliding, Earth Planets Space, 63, 773-777, 2011.

Ide, S. and G. C. Beroza, Does apparent stress vary with earthquake size? Geophys. Res. Lett., 28(17), 3349-3352, 2001.

Ide, S., A. Baltay, and G. C. Beroza, Shallow dynamic overshoot and energetic deep rupture in the $2011 \mathrm{Mw} 9.0$ Tohoku-oki Earthquake, Science, 332, 1426-1429, 2011.

Iinuma, T., M. Ohzono, Y. Ohta, and S. Miura, Coseismic slip distribution of the 2011 off the Pacific coast of Tohoku Earthquake (M9.0) estimated based on GPS data-Was the asperity in Miyagi-oki ruptured?, Earth Planets Space, 63, 643-648, 2011.

Iio, Y. and T. Matsuzawa, The generation process of the Tohoku earthquake-Why did the magnitude 9 event occur?-, J. Geol. Soc. Jpn., 118(5), 248-277, 2012 (in Japanese with English abstract).

Iio, Y., T. Matsuzawa, and M. Sato, Plate coupling before the Off-Tohoku earthquake inferred from seafloor geodetic observations, SSJ Fall Meeting 2011, P1-14, 2011 (in Japanese).

Ito, T., S. Yoshioka, and S. Miyazaki, Interplate coupling in northeast Japan deduced from inversion analysis of GPS data, Earth Planet. Sci. Lett. 176, 117-130, 2000.

Ito, Y., T. Tsuji, Y. Osada, M. Kido, D. Inazu, Y. Hayashi, H. Tsushima, R. Hino, and H. Fujimoto, Frontal wedge deformation near the source region of the 2011 Tohoku-Oki earthquake, Geophys. Res. Lett., 38(15), 2011.

Kato, A., S. Sakai, and K. Obara, A normal-faulting seismic sequence triggered by the 2011 off the Pacific coast of Tohoku Earthquake: Wholesale stress regime changes in the upper plate, Earth Planets Space, $\mathbf{6 3}$, 745-748, 2011.

Kato, N. and S. Yoshida, A shallow strong patch model for the 2011 great Tohoku-oki earthquake: A numerical simulation, Geophys. Res. Lett., 38, L00G04, doi:10.1029/2011GL048565, 2011.

Lachenbruch, A. H., Frictional heating, fluid pressure, and the resistance to fault motion, J. Geophys. Res., 85(B11), 6097-6112, 1980.

Loveless, J. P. and B. J. Meade, Spatial correlation of interseismic coupling and coseismic rupture extent of the $2011 \mathrm{Mw}=9.0$ Tohoku-oki earthquake, Geophys. Res. Lett., 38(17), doi:10.1029/2011GL048561, 2011

Ma, S. and G. C. Beroza, Rupture dynamics on a bimaterial interface for dipping faults, Bull. Seismol. Soc. Am., 98(4), 1642-1658, 2008.

Mase, C. W. and L. Smith, Effects of frictional heating on the thermal, hydrologic, and mechanical response of a fault, J. Geophys. Res., 92(B7), 6249-6272, 1987.

Meng, L., A. Inbal, and J.-P. Ampuero, A window into the complexity of the dynamic rupture of the $2011 \mathrm{Mw} 9$ Tohoku-Oki earthquake, Geophys. Res. Lett., 38, doi:10.1029/2011GL048118, 2011.

Minoura, K., F. Imamura, D. Sugawara, Y. Kono, and T. Iwashita, The 869 Jogan tsunami deposit and recurrence interval of large-scale tsunami on the Pacific coast of northeast Japan, J. Nat. Disaster Sci., 23, 83-88, 2001

Mitsui, Y. and M. Cocco, The role of porosity evolution and fluid flow in frictional instabilities: A parametric study using a spring-slider dynamic system, Geophys. Res. Lett., 37, doi:10.1029/2010GL045672, 2010.

Mitsui, Y. and K. Hirahara, Coseismic thermal pressurization can notably prolong earthquake recurrence intervals on weak rate and state friction faults: Numerical experiments using different constitutive equations, $J$. Geophys. Res., 114, doi:10.1029/2008JB006220, 2009.

Mitsui, Y. and Y. Iio, How did the 2011 off the Pacific coast of Tohoku Earthquake start and grow? The role of a conditionally stable area, Earth Planets Space, 63, 755-759, 2011. 
Mitsui, Y., N. Kato, Y. Fukahata, and K. Hirahara, Megaquake cycle at the Tohoku subduction zone with thermal fluid pressurization near the surface, Earth Planet. Sci. Lett., 325-326, 21-26, 2012.

Nielsen, S., G. Di Toro, T. Hirose, and T. Shimamoto, Frictional melt and seismic slip, J. Geophys. Res., 113, B01308, doi:10.1029/2007JB005122, 2008.

Nishimura, T., T. Hirasawa, S. Miyazaki, T. Sagiya, T. Tada, S. Miura, and K. Tanaka, Temporal change of interplate coupling in northeastern Japan during 1995-2002 estimated from continuous GPS observations, Geophys. J. Int., 157, 901-916, 2004.

Noda, H. and T. Shimamoto, Thermal pressurization and slip-weakening distance of a fault: An example of the Hanaore fault, Southwest Japan, Bull. Seismol. Soc. Am., 95(4), 1224-1233, 2005.

Ohtani, M., K. Hirahara, T. Hori, and M. Hyodo, Comparative study on quasi-dynamic earthquake cycle models for the 2011 giant Tohoku earthquake, AGU Fall Meeting 2011, U51B-0044, 2011.

Otsuki, K., N. Monzawa, and T. Nagase, Fluidization and melting of fault gouge during seismic slip: Identification in the Nojima fault zone and implications for focal earthquake mechanisms, J. Geophys. Res., 108(B4), doi:10.1029/2001JB001711, 2003.

Ruina, A., Slip instability and state variable friction laws, J. Geophys. Res., 88(B12), 10,359-10,370, 1983.

Seno, T., Determination of the pore fluid pressure ratio at seismogenic megathrusts in subduction zones: Implications for strength of asperities and Andean-type mountain building, J. Geophys. Res., 114, B05405, doi:10.1029/2008JB005889, 2009.

Shibazaki, B., T. Matsuzawa, A. Tsutsumi, K. Ujiie, A. Hasegawa, and Y. Ito, 3D modeling of the cycle of a great Tohoku-oki earthquake, considering frictional behavior at low to high slip velocities, Geophys. Res. Lett., 38(21), doi:10.1029/2011GL049308, 2011.

Sibson, R. H., Interactions between temperature and fluid pressure during earthquake faulting - a mechanism for partial or total stress relief, $\mathrm{Na}$ ture, 243, 66-68, 1973.

Suwa, Y., S. Miura, A. Hasegawa, T. Sato, and K. Tachibana, Interplate coupling beneath NE Japan inferred from three-dimensional displacement field, J. Geophys. Res., 111(B4), doi:10.1029/2004JB003203, 2006.

Suzuki, T. and T. Yamashita, Understanding of slip-weakening and -strengthening in a single framework of modeling and its seismological implications, Geophys. Res. Lett., 34, L13303, doi:10.1029/2007GL030260, 2007.

Tanaka, H., W. M. Chen, K. Kawabata, and N. Urata, Thermal properties across the Chelungpu fault zone and evaluations of positive thermal anomaly on the slip zones: Are these residuals of heat from faulting?, Geophys. Res. Lett., 34, doi:10.1029/2006GL028153, 2007.

Tanikawa, W., M. Sakaguchi, O. Tadai, and T. Hirose, Influence of fault slip rate on shear-induced permeability, J. Geophys. Res., 115, doi:10.1029/2009JB007013, 2010.
Tohoku University, Report on Observation and Research Program for Prediction of Earthquakes and Volcanic Eruptions, No. 1206, http://www.mext.go.jp/component/b_menu/shingi/toushin/ __icsFiles/afieldfile/2011/08/03/1309144_005.pdf, 2010 (in Japanese).

Tsuji, T., T. Kanamatsu, K. Kawamura, K. Arai, K. Fujikura, Y. Ito, J. Ashi, M. Kinoshita, and T. Matsuoka, Fault system and dynamic seafloor deformation in the 2011 Tohoku earthquake, AGU Fall Meeting 2011, U41D-02, 2011.

Tsutsumi, A., S. Nishino, K. Mizoguchi, T. Hirose, S. Uehara, K. Sato, W. Tanikawa, and T. Shimamoto, Principal fault zone width and permeability of the active Neodani fault, Nobi fault system, Southwest Japan, Tectonophysics, 379, 93-108, 2004.

Uchida, N. and T. Matsuzawa, Coupling coefficient, hierarchical structure, and earthquake cycle for the source area of the 2011 off the Pacific coast of Tohoku earthquake inferred from small repeating earthquake data, Earth Planets Space, 63, 675-679, 2011.

Uchida, N., T. Matsuzawa, S. Hirahara, and A. Hasegawa, Small repeating earthquakes and interplate creep around the 2005 Miyagi-oki earthquake $(M=7.2)$, Earth Planets Space, 58, 1577-1580, 2006.

Ujiie, Y., A. Tsutsumi, Y. Fialko, and H. Yamaguchi, Experimental investigation of frictional melting of argillite at high slip rates: Implications for seismic slip in subduction-accretion complexes, J. Geophys. Res., 114, B04308, doi:10.1029/2008JB006165, 2009.

Wessel, P. and W. H. F. Smith, New version of the generic mapping tools released, Eos Trans. AGU, 76, 329, 1995.

Yagi, Y. and Y. Fukahata, Rupture process of the 2011 Tohoku-oki earthquake and absolute elastic strain release, Geophys. Res. Lett., 38, doi:10.1029/2011GL048701, 2011.

Yamanaka, Y. and M. Kikuchi, Asperity map along the subduction zone in northeastern Japan inferred from regional seismic data, J. Geophys. Res., 109(B7), doi:10.1029/2003JB002683, 2004.

Yao, H., P. Gerstoft, P. M. Shearer, and C. Mecklenbrauker, Compressive sensing of the Tohoku-Oki Mw 9.0 earthquake: Frequency-dependent rupture modes, Geophys. Res. Lett., 38, doi:10.1029/2011GL049223, 2011.

Yoshida, Y., H. Ueno, D. Muto, and S. Aoki, Source process of the 2011 off the Pacific coast of Tohoku Earthquake with the combination of teleseismic and strong motion data, Earth Planets Space, 63, 565-569, 2011.

Zhao, D., Z. Huang, N. Umino, A. Hasegawa, and H. Kanamori, Structural heterogeneity in the megathrust zone and mechanism of the 2011 Tohoku-oki earthquake (Mw 9.0), Geophys. Res. Lett., 38, doi:10.1029/2011GL048408, 2011.

Y. Mitsui (e-mail: ymitsui@mail.sci.hokudai.ac.jp), Y. Iio, and Y. Fukahata 